\title{
A review of 100 consecutive free flaps
}

\author{
Dale A Classen MD FRCSC \\ Division of Plastic Surgery, Department of Surgery, Royal University Hospital, Saskatoon, \\ Saskatchewan
}

DA Classen. A review of 100 consecutive free flaps. Can J Plast Surg 1999;7(6) 279-284.

This study is an analysis of the first 100 consecutive free flaps performed by the author. During a 61 month period, 100 free flaps were performed in 90 patients. The overall flap success rate was $93 \%$. A review of the indications, donor sites, recipient sites, outcomes and complications is presented. A comparison is made between the first 50 free flaps and the second 50 free flaps to examine evolving practice patterns. Techniques that were of value are discussed.

Key Words:Complications; Free flap; Results

\section{Revue de 100 lambeaux libres consécutifs}

RÉSUMÉ : Cette étude est une analyse des 100 premiers lambeaux libres consécutifs effectués par l'auteur. Au cours d'une période 61 mois, 100 lambeaux libres ont été effectués chez 90 patients. Le taux de réussite globale a été de $93 \%$. On fait ici le bilan des indications, des sites donneurs, des sites receveurs, de l'issue du traitement et de ses complications. On établit une comparaison entre les 50 premiers lambeaux libres et les 50 suivants afin de vérifier l'évolution de la pratique. Les techniques utiles sont aussi décrites.

$\mathrm{T}$

This study analyzes the first 100 consecutive free flaps performed by the author. Data were collected prospectively in a microsurgical data base as part of an ongoing review of the microsurgical experience of all patients undergoing free flap reconstructions The data were reviewed in a retrospective fashion. The review comprised 100 consecutive free flaps performed between January 1994 and February 1999 in 90 patients. Nine patients had two free flaps transferred to either bilateral extremity wounds, or complex facial or hand wounds. One patient had a second free flap performed to the same wound after failure of the first free flap. There were 58 men and 32 women. The age range was from eight to 80 years with an average age of 37 years. Ten patients were older than 65 years of age.

\section{Indications}

\section{RESULTS}

The indications for free flap transfer are outlined in Table 1. The vast majority $(82 \%)$ of free flaps were performed for wounds related to trauma. This includes both acute and chronic traumatic wounds. The majority of these free flaps were to provide soft tissue coverage. The etiology of the trau-

Correspondence: Dr DA Classen, Division of Plastic Surgery, Department of Surgery, Royal University Hospital, 103 Hospital Drive, Saskatoon, Saskatchewan, S7N 0W8. Telephone 306-966-7782,

Fax306-242-3703,e-mail jdclassen@home.com matic wounds is indicated in Table 2 . The majority of the wounds were related to motor vehicle accidents.

\section{Donor sites}

A muscle free flap was used in $60 \%$ of the cases. The latissimus dorsi muscle and rectus abdominis muscle free flaps accounted for $58 \%$ of all muscle free flaps. A fasciocutaneous free flap was performed in $34 \%$ of cases. The scapular free flap and lateral arm free flap accounted for $76 \%$ of all fasciocutaneous free flaps. A complete breakdown of donor site flaps is outlined in Table 3.

\section{Recipient sites}

The majority of recipient sites $(67 \%)$ were located in the lower extremity. Seventeen per cent of recipient sites were located in the head and neck region. Thirteen per cent of recipient sites were in the upper extremity or hand region. Table 4 summarizes the recipient site locations, free flaps transferred and the outcome.

\section{Recipient Vessels}

Arterial anastomoses were performed with an end-to-side technique in $62 \%$ of cases or as an end-to-end technique in $38 \%$ of cases. The type of arterial anastomosis performed generally depended on the recipient site. Seventy-one per cent of lower extremity arterial anastomoses were performed with an end-to-side technique. Ninety-two per cent of upper 
TABLE 1

Indication for free flap transfer in 100 consecutive free flaps performed between January 1994 and February 1999

\begin{tabular}{lc}
\hline Indication & Number \\
\hline Trauma & 82 \\
Cancer & 8 \\
Ulcers & 7 \\
Other & 3 \\
\hline
\end{tabular}

TABLE 2

Etiology of traumatic wounds in 100 consecutive free flaps performed between January 1994 and February 1999

\begin{tabular}{lc}
\hline Etiology & Number \\
\hline Motor vehicle accident & 32 \\
Gunshot wound & 9 \\
Frostbite & 9 \\
Farm accident & 8 \\
Burns & 7 \\
Industrial accident & 7 \\
Falls & 4 \\
Train & 4 \\
Lawn mower & 2 \\
\hline
\end{tabular}

extremity flaps were anastomosed with an end-to-side technique. Ninety-four per cent of the head and neck free flaps were anastomosed in an end-to-end fashion to a branch of the external carotid artery.

The venous anastomosis was most commonly performed as an end-to-end anastomosis (67\%). Vein grafts were electively used in $8 \%$ of cases. There was an $88 \%$ success rate with elective vein graft use. Vein grafts were used in salvage re-exploration in three cases, and were successful in flap salvage in two cases.

\section{Complications and outcomes}

Table 5 summarizes complications. The flap complication rate was $27 \%$. The most common flap complication was total flap loss $(7 \%)$. Therefore, the overall free flap success rate was $93 \%$. The take back rate for re-exploration of a compromised flap was $5 \%$. The salvage rate of re-explored flaps was $40 \%$ (ie, two of five re-explored flaps were salvaged). The incidence of infection was $1 \%$. There was a $2 \%$ incidence of hematoma requiring evacuation.

The overall donor site complication rate was $10 \%$. The majority of these complications were seromas from latissimus dorsi donor sites. Two complications required reoperation. One patient developed carpal tunnel syndrome after a radial forearm flap, which required decompression four months postoperatively. One patient had a loss of $20 \%$ of skin graft on the radial forearm donor site; the graft had to be redone.

The overall systemic or generalized complication rate was $27 \%$. One-third of these complications were urinary tract infections or postoperative delirium. One obese patient re-
TABLE 3

Free flap donor sites in $\mathbf{1 0 0}$ consecutive free flaps performed between January 1994 and February 1999

\begin{tabular}{lc}
\hline Donor site & Number \\
\hline Muscle $(\mathrm{n}=60)$ & 20 \\
Latissimus dorsi & 15 \\
Rectus abdominis & 13 \\
Gracilis & 8 \\
Latissimus/serratus & 4 \\
Serratus & \\
Fasciocutaneous ( $\mathrm{n}=34)$ & 16 \\
Scapular & 10 \\
Lateral arm & 6 \\
Radial forearm & 1 \\
Dorsalis pedis & 1 \\
Scalp & \\
Myocutaneous ( $\mathrm{n}=2)$ & 2 \\
Rectus abdominis & 2 \\
Jejunum & 1 \\
Fibula & \\
Radial forearm osteocutaneous & \\
\hline
\end{tabular}

quired a second operation for release of a thigh compartment syndrome detected postoperatively after being in a lateral decubitus position for $6 \mathrm{~h}$. Four cases of temporary neuropraxias, resolved spontaneously.

\section{DISCUSSION}

This series of 100 consecutive free flaps in 90 patients is a review of personal experience over the last five years. The main indication was for traumatic wounds, predominantly on the lower extremity. The results compare favourably with those of other reports of similar groups of patients $(1,2,3)$.

The success rate of free flap surgery has risen steadily over the last two decades, with a corresponding decline in the thrombosis rate (4). This improvement has been attributed to accumulated experience and a better understanding of the causes of flap failure and ways to avoid them (5).

Although some authors dispute the notion that accumulated experience translates into improved results (6), the data in Table 6 tend to support this idea. Table 6 is an analysis of the 100 free flaps, divided into two groups. Group 1 was the first 50 free flaps, group 2 was the second 50 free flaps. With accumulated experience (comparing group 2 to group 1) there is an increased success rate (94\% versus $92 \%$ ), a decreased take back rate ( $4 \%$ versus $6 \%$ ), an increased salvage rate of take backs (50\% versus $33 \%$ ) and a decreased rate of anastomotic revisions ( $2 \%$ versus $6 \%$ ) were noted. There was also a decline in average operative time by $30 \mathrm{mins}$ and a decline in average total flap ischemia time by 18 mins.

The following discussion outlines some technical aspects of the evolution of free flap procedures that aided in achieving the successful outcomes for this series of patients. 
TABLE 4

Free flaps by location and outcome in 100 consecutive free flaps performed between January 1994 and February 1999

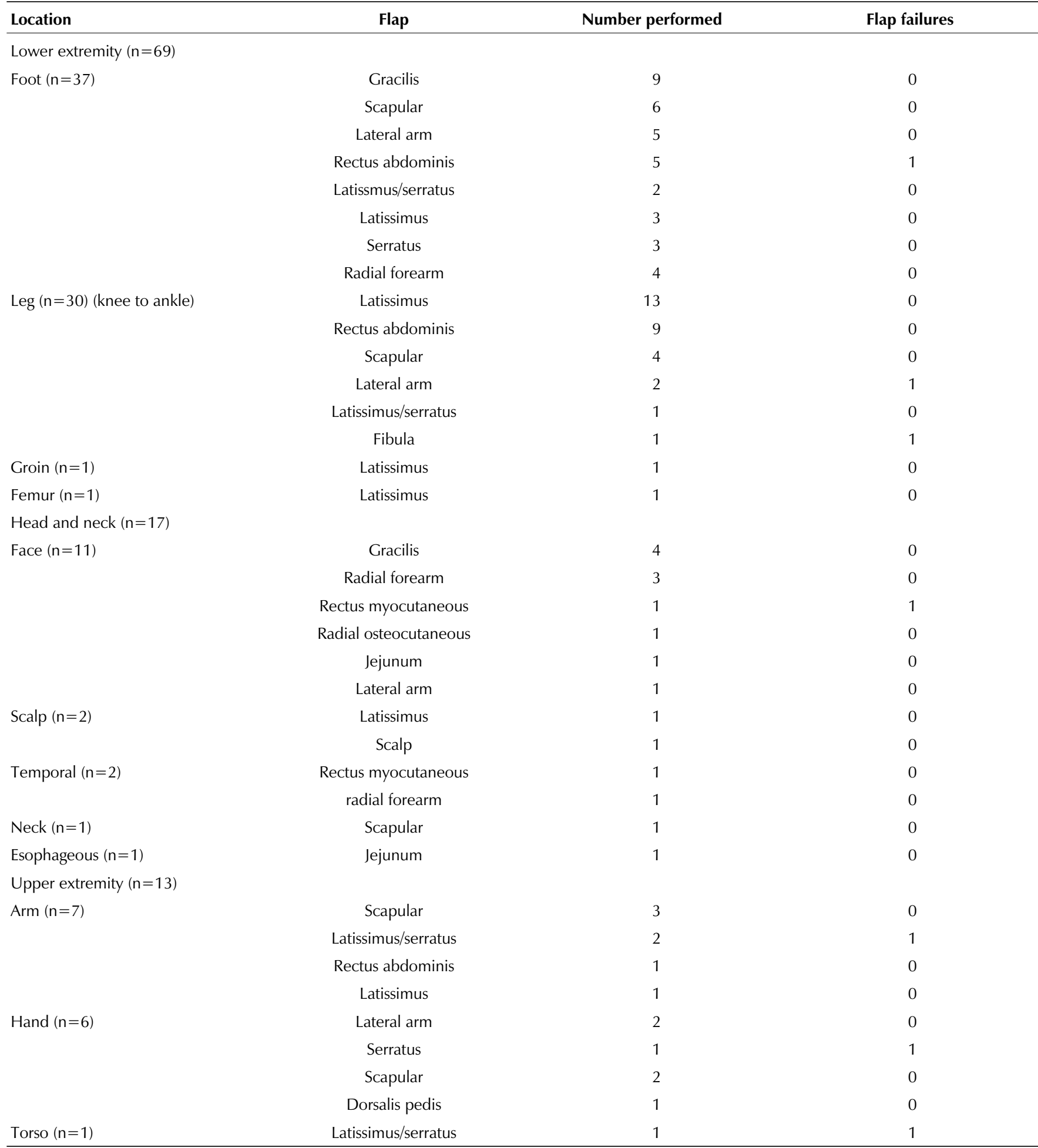

\section{Donor sites}

Although the two groups were relatively similar with respect to wound etiology and patient age, there were considerably more muscle free flaps performed in group $2(78 \%)$ versus group $1(42 \%)$. The increased use of muscle flaps in group 2 was related to their ability to contour and fill wounds better and to their requirement for fewer secondary debulking pro- cedures. A total of six secondary debulking procedures were performed in group 1. All debulking procedures were performed on fasciocutaneous flaps. None were required in the last 50 free flaps (group 2). The lower incidence of secondary debulking procedures in group 2 is attributed to a better designed fasciocutaneous flap and to the increased use of muscle free flaps. 
TABLE 5

Complications in 100 consecutive free flaps performed between January 1994 and February 1999

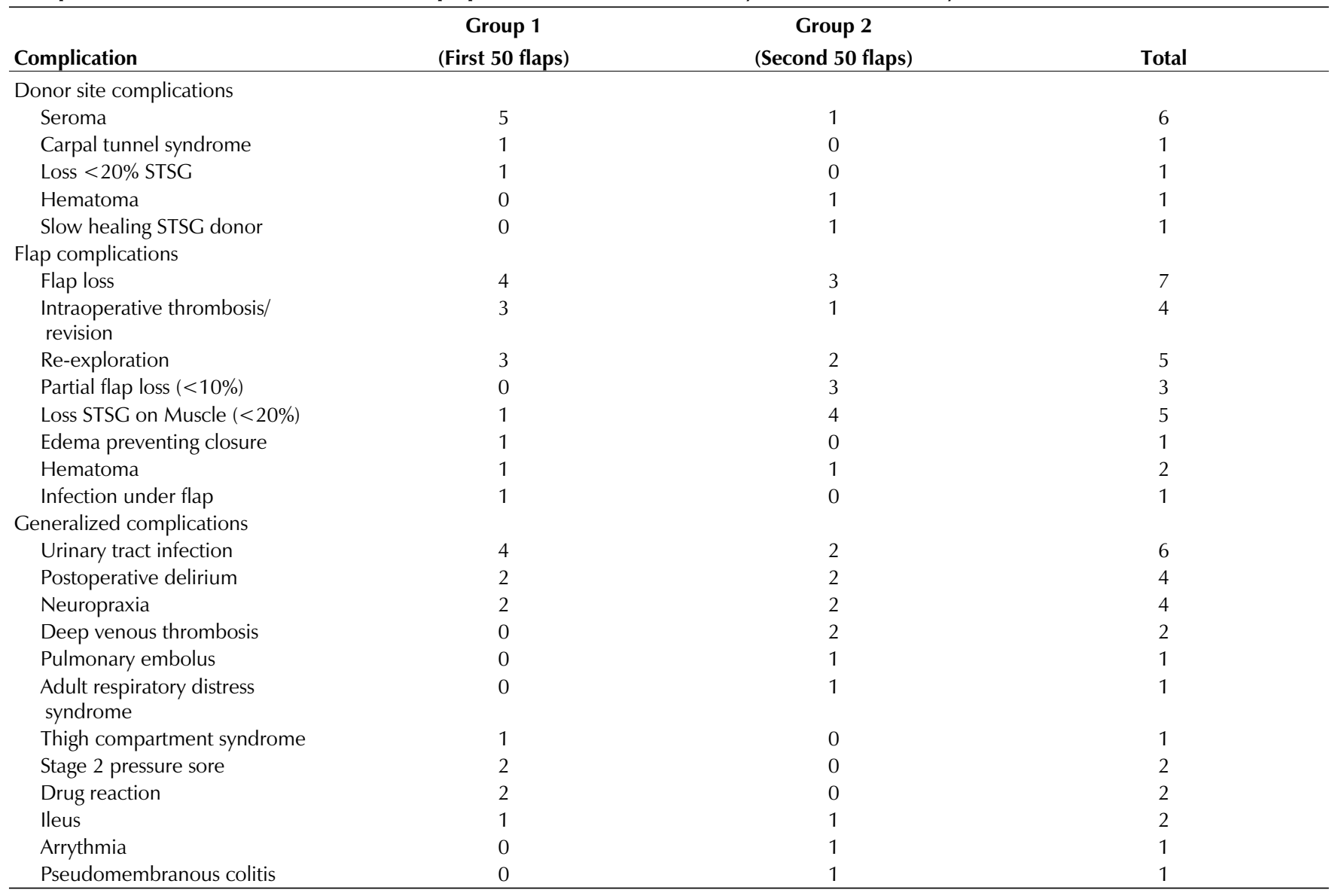

STSG Split-thickness skin graft

The combined latissimus/serratus muscle free flap has been a very useful flap (7). The ability to transfer two independent muscle flaps based on a single vascular pedicle has aided in the closure of complex bilateral malleolar wounds, anterior and posterior foot wounds, and large extremity wounds.

A useful adjunct in the harvest of the gracilis muscle during facial reanimation has been described (8). This entails the use of a GIA stapler (Ethicon Endosurgery Inc, Cincinatti, Ohio) to achieve hemostasis during muscle harvest and to provide a firm origin to suture the muscle for inset. This technique was used on several occasions in the last few months of this review and certainly simplifies gracilis muscle harvest and inset when used for facial reanimation.

\section{Recipient sites}

In lower extremity reconstruction, use of uninjured vessels proximal to the zone of injury for microanastomosis was generally preferred. However, there have been recent reports documenting the success of performing the microanastomosis distal to the zone of injury in selected patients $(9,10)$. This was used successfully on three occasions in the last 50 free flaps. In each situation, the alternative would have required vein grafting to reach proximal uninjured vessels. Although vein grafting has been used successfully, its avoidance sim- plifies the overall operative procedure. Access to vessels for anastomosis is critical to success. Liberal use of the lateral decubitus position to access the posterior tibial vessels, and the use of a Penrose drain (Sherwood Medical Company, St. Louis Missouri) drain to aid in exposure of the anterior tibial vessels, have proven useful (11).

Another useful technique to aid in flap inset in the lateral ankle region is passage of the flap through the calcaneal subtendinous space when using the posterior tibial vessels for anastomosis. This has been described previously by Lister Rockwell et al (12), and has been used to shorten the distance between the lateral ankle wound and the pedicle anastomosis when using the posterior tibial vessels.

With respect to vascular anastomoses, there has been a relatively equal use of end-to-side arterial anastomosis techniques throughout this study. However, there was much greater reliance on end-to-end venous anastomosis in the last 50 free flaps (98\%) compared with the first 50 free flaps (44\%). The use of end-to-end techniques for venous anastomosis has reduced the anastomotic time requirements. All end-to-side anastomoses were performed with a running 8-0 or 9-0 nylon suture. All end-to-end anastomoses were performed with an interrupted 8-0 or 9-0 nylon suture.

Vein grafts were used with equal frequency in both groups $(8 \%)$. When both arterial and venous interposition vein grafts 
TABLE 6

Summary of 100 consecutive free flaps performed between January 1994 and February 1999

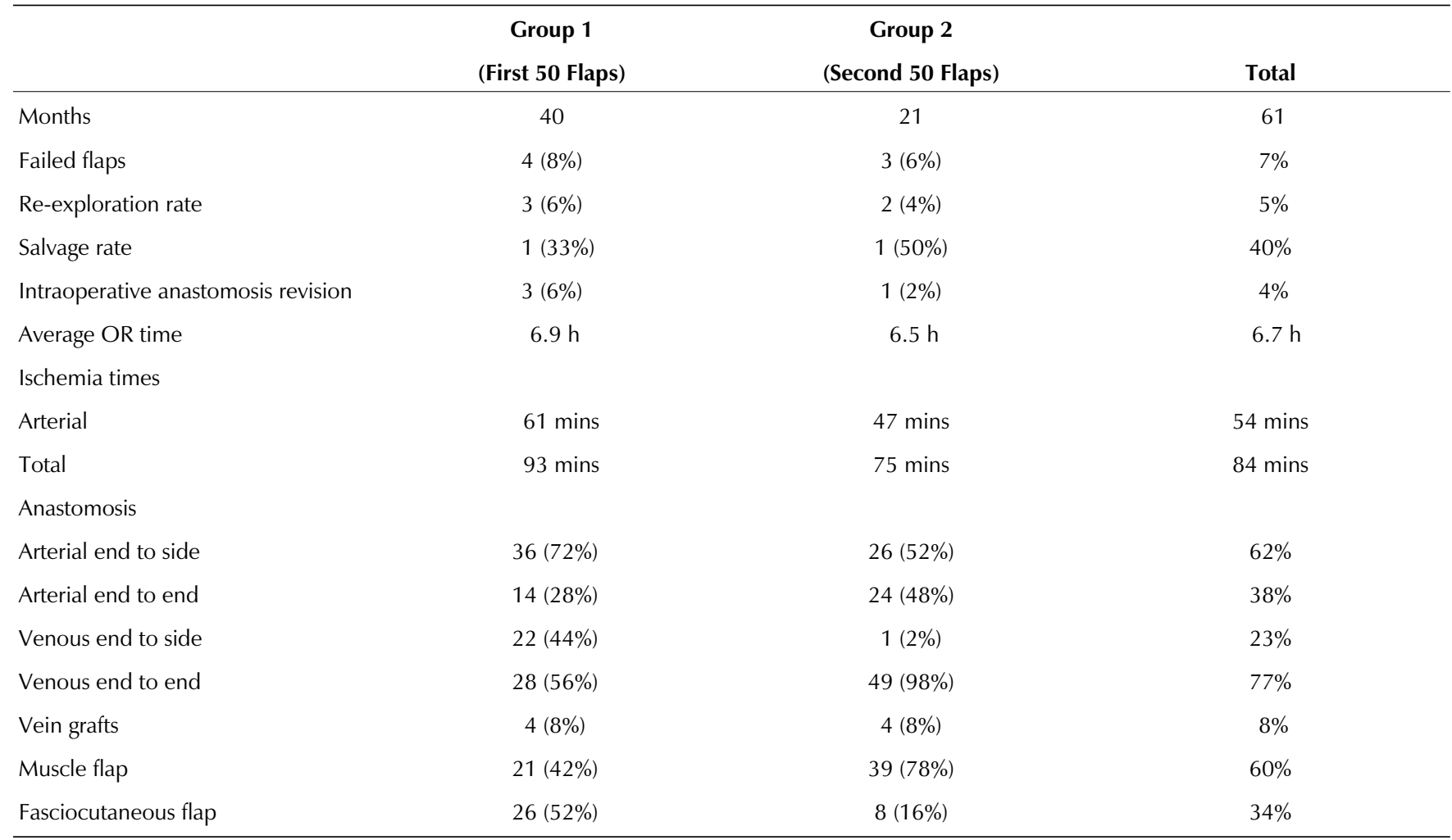

were required, the vein grafts were placed as a temporary arterial venous fistula, which minimizes flap ischemia time (13).

\section{Postoperative regimen}

The anticoagulation regimen was not altered for this series of patients. All microvascular repairs were irrigated with heparinized ringers lactate solution. A single intravenous heparin bolus of 2000 to 3000 units was given just before the flap pedicle was harvested. Postoperatively, a patient received 325 $\mathrm{mg}$ of acetylsalicylic acid orally for two weeks, and 5000 units of subcutaneous heparin twice daily, until he or she was mobilized. Although no standardized protocol has been proved conclusively to affect thrombosis rates, heparinized irrigation appears to be of benefit (14). Subcutaneous postoperative heparin has been shown to lower postoperative thrombosis rates (15), and there is some support for the use of postoperative acetylsalicylic acid (16). The postoperative hematoma rate of $2 \%$ in this series of patients suggests that the above regimen was relatively safe and compares favourably with other series $(17,18)$.

\section{Complications}

Analysis of complications demonstrates a declining incidence in virtually all complications with ongoing experience. With respect to total flap failures, the incidence was $8 \%$ of the first 50 free flaps and $6 \%$ of the second 50 free flaps. There was a decline in incidence of failure and also a change in the etiology of failure. Of the first 50 free flaps, four flaps were lost due to technical failures. One flap was lost on postoperative day 1 due to a twisted pedicle. One flap was lost on postoperative day 0 due to a venous thrombosis secondary to a valve cusp in the site of anastomosis. Two flaps were lost intraoperatively due to prolonged ischemia secondary to failed revascularization of the flaps. Of the last 50 free flaps, three flaps were lost, two cases were likely due to systemic problems rather than purely technical problems. One flap was lost on postoperative day 10 due to venous thrombosis in a patient who developed adult respiratory distress syndrome. One flap was lost on postoperative day 4 due to severe arterial spasm in a patient with a history of heavy smoking and anxiety within hours after the removal of his epidural catheter. The third flap loss in group 2 was a buried fibula flap for a six centimeter tibia defect in an eight-yearold boy. Postoperative bone scan at day 5 demonstrated a lack of bone perfusion. The etiology of this failure is unclear.

Re-exploration was performed in three flaps in group 1 . One flap was a salvaged. Re-exploration was performed in two flaps in group 2, with one flap salvaged. Both cases salvaged were compromised flaps with venous thrombosis in the recipient vein, which was corrected by vein grafting beyond the area of the injured vein.

\section{CONCLUSIONS}

In summary, this review of 100 consecutive free flaps reveals an overall flap success rate of $93 \%$. A review of this study demonstrates that, with experience, there has been a 
slight improvement in flap survival, a decreased incidence of intraoperative anastomotic revision, a decreased rate of flap take back and a change in the etiology of flap failure.

\section{REFERENCES}

1. Irons GB, Wood MB, Schmidt EH. Experience with one hundred consecutive free flaps. Ann Plast Surg 1987;18:17-23.

2. Khouri RK, Shaw WW. Reconstruction of the lower extremity with microvascular free flaps: A 10 year experience with 304 consecutive cases. J Trauma 1989;29(8):1086-94.

3. Melissinos EG, Parks DH. Post-trauma reconstruction with free tissue transfer-analysis of 442 consecutive cases. J Trauma 1989;29:1095-102.

4. Khouri RK. Free flap surgery-the second decade. Clin Plast Surg 1992;19:757.

5. Khouri RK. Avoiding free flap failure. Clin Plast Surg 1992;19:773-81.

6. Bonawitz SC, Schnarrs RH, Rosenthal AI, et al. Free-tissue transfer in elderly patients. Plast Reconstr Surg 1991;87:1074-9.

7. Hallock GG. Permutations of combined free flaps using the subscapular system. J Reconstr Microsurg 1997;13:47-54.8.

8. Turkowski GA, Koshima I, Upton J. Muscle stapling technique for free muscle transfer to the face. Plast Reconstr Surg 1998;102:1639.
9. Stompro BE, Stevenson TR. Reconstruction of the traumatized leg: Use of distally based free flaps. Plast Reconstr Surg 1994;93:1021-5.

10. Kolker AR, Kasabian AK, Karp NS, et al. Fate of free flap microanastomosis distal to the zone of injury and lower extremity trauma. Plast Reconstr Surg 1997;99:1068-73.

11. Celebi C, Atabay K, Cenetoglu S, et al. Elevation of deeply located vascular structures in order to facilitate end to side anastomosis. Plast Recontr Surg 1991;87:1129-30.

12. Rockwell WB, Cheng CA, Lister GD. The calcaneal subtendinous space for passage of the pedicle in free flap reconstruction of lateral ankle defects. Plast Recontr Surg 1998;101:442-4.

13. Hallock GG. The interposition arteriovenous loop revisited. J Reconstr Microsurg 1988;4:155-9.

14. Reichel CA, Croll GH, Puckett CI. A comparison of irrigating solutions for microanastomosis. J Hand Surg 1988;13A:33.

15. Khouri RK, Cooley BC, Kunselman AR, et al. A prospective study of microsvascular free flap surgery and outcome. Plast Reconstr Surg 1998;102:711-21.

16. Johnson PC, Barker JH. Thrombosis and antithrombotic therapy and microvascular surgery. Clin Plast Surg 1992;19:799-807.

17. Kroll SS, Miller MJ, Reece GP, et al. Anticoagulants and hematomas in free flap surgery. Plast Reconstr Surg 1995;96:643-7.

18. Reus WF, Colen LB, Straker DJ. Tobacco smoking and complications in elective microsurgery. Plast Reconstr Surg 1992;89:490-4. 